\title{
Hubungan antara Program Expanding Maternal And Neonatal Survival (Emas) dengan Peningkatan Pengetahuan, Sikap dan Perilaku Bidan dalam Pengelolaan Kasus Kegawatdaruratan Obstetrik Pra Rujukan
}

\author{
Wiwik Widyaningsih ${ }^{1}$, Risanto Siswosudarmo ${ }^{2}$, Soerjo Hadijono ${ }^{3}$ \\ ${ }^{1}$ RS PKU Muhammadiyah Gombong \\ ${ }^{2}$ Departemen Obstetri dan Ginekologi, FKKMK, UGM \\ ${ }^{3}$ Departemen Obstetri dan Ginekologi, FK UNDIP \\ Korespondensi: wiwikusodo@gmail.com
}

Submisi:10 Oktober 2018; Revisi: 19 Desember 2018; Penerimaan: 20 Desember 2018

\begin{abstract}
Background: The absolute number of maternal mortality in Kebumen District in 2014 was 12 largely due to postpartum hemorrhage and severe preeclampsia (PEB). In the EMAS program, one of the activities is to increase knowledge and skills for the management of postpartum hemorrhage and severe preeclampsia (PEB).

Objective: To find out the relationship between exposure to the EMAS program in terms of knowledge, attitudes and behavior of midwives when managing pre-referral obstetric emergency cases.

Method: This study uses a cross sectional design, carried out on midwives who refer to cases of postpartum hemorrhage and severe pre-eclampsia in the PKU Muhammadiyah Gombong General Hospital Emergency Room from 2014-2015. The questionnaire used was assessed with a Likert scale, assessing knowledge with the true-false questionnaires, while the skills with a skill checklist scored from 10 to 100 according to performance procedure as expected.

Results and Discussion: A total of 104 respondents (midwives), consisting of 52 midwives who were exposed to the EXPANDING MATERNAL AND NEONATAL SURVIVAL (EMAS) program and 52 midwifes not affected by the EMAS program (control). They are comparable in age, years of service (work experience), and attedance in PPGDON training. Bivariate analysis shows that exposure to the EMAS program is significantly associated with increasing knowledge, attitudes and behavior of midwives in the field of obstetric emergencies. The results of logistic regression analysis showed that the EMAS program was associated with the results of an increase in active management knowledge at the third stage (OR: 6.41; 95\% $\mathrm{Cl}$ 2.32-17.72); preeclampsia knowledge (OR: 11.72; 95\% Cl 4.19-32.78); active management attitude at the third stage (OR: $2.97 ; 95 \% \mathrm{Cl} 1.11-7.91)$; preeclampsia attitude (OR $25.87 ; 95 \% \mathrm{Cl} 8.17-81.90)$. The relationship with active management skills at the third stage (OR: 7.37; $95 \% \mathrm{Cl}$ 2.10-25.85) and preeclampsia skills (OR: $26.64 ; 95 \% \mathrm{Cl} 7.98-88.96$ ).

Conclusion: There is a relationship between the Maternal and Neonatal Survival Expanding Program and the improvement of the skills, attitudes and behavior of midwives in the field of obstetric emergency case management pre-treatment.
\end{abstract}

Keywords: Expanding Maternal and Neonatal Survival (EMAS); knowledge; attitudes; behavior; handling obstetric emergency referral.

\begin{abstract}
ABSTRAK
Latar Belakang: Angka kematian absolut ibu di Kabupaten Kebumen tahun 2014 adalah 12yang sebagian besar disebabkan oleh perdarahan pascasalin dan preeklampsia berat (PEB). Dalam program EMAS salah satu kegiatan adalah peningkatan pengetahuan dan ketrampilan untuk penatalaksanaan perdarahan pascasalin dan preeklampsia berat (PEB).

Tujuan: Untuk mengetahui hubungan paparan program EMAS dalam hal pengetahuan, sikap dan perilaku bidan saat mengelola kasus kegawatdaruratan obstetrik pra rujukan.

Metode: Penelitian ini menggunakan desain cross sectional, dilaksanakan terhadap bidan yang merujuk kasus perdarahan postpartum dan pre eklampsia berat di IGD RSU PKU Muhammadiyah Gombong dari tahun 2014-2015. Kuesioner yang digunakan dinilai dengan skala Likert, menilai pengetahuan dengan kuesioner benar salah, sedangkan ketrampilan dengan daftar tilik keterampilan nilai dari 10 sampai 100 kalau menjalankan prosedur sesuai harapan.

Hasil dan Pembahasan: Sebanyak 104 responden (bidan), yang terdiri dari 52 bidan yang terpapar program EXPANDING MATERNAI AND NEONATAL SURVIVAL (EMAS) dan 52 lainnya adalah responden tang tidak terkena program EMAS (kontrol). Mereka sebanding dalam usia, tahun pelayanan (pengalaman kerja), dan keikutsertaan dalam pelatihan PPGDON. Analisis bivariat menunjukkan bahwa paparan program EMAS berhubungan secara signifikan dengan peningkatan pengetahuan, sikap dan perilaku bidan di bidang kegawatdaruratan kebidanan. Hasil analisis regresi logistik menunjukkan bahwa program EMAS berhubungan dengan hasil peningkatan pengetahuan managemen aktif kala III (OR: 6,41; 95\% Cl 2,32-17,72); pengetahuan PEB (OR: 11,72; 95\% Cl 4,19-32,78); sikap managemen aktif kala III (OR: 2,97; 95\%Cl 1,11-7,91); sikap PEB (OR 25,87; 95\% Cl 8,17-81,90). Hubungan dengan keterampilan managemen aktif kala III (OR: 7,37; 95\% $\mathrm{Cl} 2,10-25,85)$ dan keterampilan PEB (OR: 26,64; $95 \% \mathrm{Cl} 7,98-88,96)$.

Kesimpulan: Terdapat hubungan antara Program Expanding Maternal and Neonatal Survival dengan peningkatan kemampuan, sikap dan perilaku bidan di bidang pengelolaan prarujukan kasus kegawatdaruratan obstetrik.
\end{abstract}

Kata kunci: Expanding Maternal and Neonatal Survival (EMAS); pengetahunan; sikap; perilaku; penanganan prarujukan kegawatdaruratan obstetri. 


\section{PENDAHULUAN}

Melihat masih tingginya angka kematian ibu dan bayi, maka Kementerian Kesehatan Indonesia melakukan kerjasama dengan United State Agency for International Development ( USAID) untuk menurunkan Angka Kematian Ibu (AKI) dan Angka Kematian Bayi (AKB) melalui program Expanding Maternal and Neonatal Survival (EMAS) selama 5 tahun (2012-2016). Program EMAS merupakan bagian dari Kemitraan Komprehensif antara Amerika Serikat dan Indonesia, dimana kedua pemimpin Negara tersebut telah menegaskan kembali komitmennya untuk bekerjasama di bidang kesehatan dan pencapaian Millenium Development Goals (MDG). ${ }^{1}$

Angka kematian absolut ibu di Kabupaten Kebumen tahun 2014-2015 adalah 12 dengan kasus terbanyak disebabkan oleh perdarahan pasca salin dan pre eklampsia berat (PEB). ${ }^{2}$ Hampir seluruh pasien pre eklampsia berat (PEB) yang dirujuk ke Rumah Sakit sudah terlambat dan belum mendapatkan terapi dengan magnesium sulfat dosis awal yang seharusnya diberikan sebelum rujukan / pra rujukan.

Dalam program EMAS salah satu kegiatan adalah peningkatan pengetahuan dan ketrampilan untuk penatalaksaan perdarahan pasca salin dan pre eklampsia berat (PEB), bahkan salah satu target program adalah tercapainya pengetahuan dan keterampilan tenaga kesehatan (bidan) untuk memberikan dosis awal magnesium sulfat pra rujukan yang dicatat dalam pelaporan jumlah cakupan pemberian magnesium sulfat pra rujukan oleh tenaga kesehatan (bidan). ${ }^{3}$ Peningkatan pengetahuan dan keterampilan tersebut dilakukan dengan cara pendampingan dan simulasi (driil) kegawatdaruratan obstetri ${ }^{4}$ Target program tersebut selain untuk menurunkan angka kematian ibu juga untuk menurunkan angka nyaris mati pada ibu bersalin yang disebabkan oleh karena komplikasi kehamilan maupun persalinan. Di dalam program EMAS kriteria kasus nyaris mati diantaranya: mendapatkan tranfusi 2 (dua) kantong, pasien masuk ICU, pasien dilakukan relaparatomi, pasien dengan eklampsia dan pre eklamsia berat dan juga sepsis.
Program EMAS ini bisa disebar luaskan di wilayah Kabupaten Kebumen agar kedepannya dalam penatalaksanaan pre eklampsia berat (PEB) bisa ditingkatkan cakupan pemberian dosis awal magnesium sulfat sebelum rujukan dan management aktif kala III. Penelitian ini bertujuan untuk menilai paparan intervensi EMAS dengan pengetahuan keterampilan bidan dalam pra rujukan gawat darurat obstetri.

\section{METODE}

Penelitian observasional dengan rancangan cross secsional dan pendekatan kuantitatif dilakukan untuk mendukung tercapainya tujuan penelitian ini. Data yang dikumpulkan diambil dari hasil jawaban kuisener. ${ }^{5}$ Penelitian dilakukan di RSU PKU Muhammadiyah Gombong, Puskesmas Karanganyar Kabupaten Kebumen dan Puskesmas Tambak serta Sumpyuh. Populasi adalah bidan yang melakukan rujukan ke RSU PKU Muhammadiyah Gombong. Penentuan besar sampel dalam penelitian ini ditentukan dengan pengamatan sementara bahwa $10 \%$ bidan yang belum terpapar berani menyuntik magnesium sulfat, mereka yang sudah terpapar EMAS 90\%. Hasil perhitungan besar sampel yang dibutuhkan sebanyak 50 subyek pada msing-masing kelompok.

Sumber data yang digunakan dalam penelitian ini menggunakan data yang dikumpulkan dari kuisioner. Data nilai keterampilan diambil dari penilaian keterampilan klinik berdasarkan daftar tilik keterampilan. Analisis univariat dilakukan dengan melihat distribusi frekwensi, kemudian analisis bivariat untuk menilai hubungan antar dua variabel dilakukan dengan $\mathrm{T}$ tes Chi Square, dan yang terakhir mencari variabel yang paling berpengaruh menggunakan analisis multivariat (regresi logistik).

\section{HASIL DAN PEMBAHASAN}

\section{Karakteristik Responden}

Keseluruhan jumlah responden adalah 104 bidan. Kelompok program EMAS sejumlah 52 bidan dan untuk kelompok kontrol 52 bidan. Komparabilitas responden dapat dilihat dalam tabel 1. 
Tabel 1. Tabel komparabilitas antar kelompok responden

\begin{tabular}{lccccc}
\hline \multirow{2}{*}{ No karakteristik } & \multicolumn{2}{c}{ EMAS } & \multicolumn{2}{c}{ KONTROL } & Nilai $P$ \\
\cline { 2 - 6 } & $\mathrm{N}$ & $\%$ & $\mathrm{~N}$ & $\%$ & \\
\hline Umur (tahun) & & & & & \\
$\quad<30$ & 26 & 47,3 & 29 & 52,7 & 0,56 \\
$\quad 26$ & 53,1 & 23 & 46,9 & \\
$\quad \begin{array}{l}\text { Pelatihan } \\
\quad \text { PPGDON }\end{array}$ & 35 & 51,5 & 33 & 48,5 & 0.68 \\
$\quad$ Tidak & 17 & 47,2 & 19 & 52,8 & \\
\hline Lama bekerja (tahun) & & & & & \\
$\quad<5$ tahun & 18 & 42,9 & 24 & 57,1 & 0.23 \\
$\quad 25$ tahun & 34 & 54,8 & 28 & 45,2 & \\
\hline
\end{tabular}

Dari data tersebut variabel yang berpotensi mengganggu outcome (hasil yang diharapkan) tampak sebanding.

\section{Hubungan Program EMAS terhadap hasil yang diharapkan (outcome)}

Analisis hubungan antara pengetahuan, sikap dan perilaku bidan dalam hal penanganan kegawat daruratan khususnya management aktif kala tiga dan pemberian magnesium sulfat pada kasus pre eklampsia berat dilakukan dengan Chi Square. Untuk penilaian pengetahuan nilai $<80$ dianggap kurang mampu (kurang baik) dan $\geq 80$ dianggap mampu (baik). Untuk penilaian sikap nilai< 40 dianggap sikap yang kurang mendukung (kurang baik) dan $\geq$ 40 dianggap mendukung (baik). ${ }^{6}$ Untuk penilaian keterampilan nilai dibawah 80 dianggap kurang terampil (kurang baik) dan $\geq 80$ dianggap terampil (baik). Masing masing di jelaskan pada tabel 2.

Tabel 2. Hubungan antara program EMAS dengan pengetahuan, sikap dan perilaku bidan terhadap managemen aktif kala 3 dan pre eklampsia berat pra rujukan.

\begin{tabular}{|c|c|c|c|c|}
\hline Kelompok & Baik & Kurang & $\%$ & $\mathrm{RR}(\mathrm{Cl})$ \\
\hline \multicolumn{5}{|c|}{ Pengetahuan Manajemen Aktif Kala III } \\
\hline EMAS & 49 & 3 & 94,2 & $1,75(1,35-2,27)$ \\
\hline Kontrol & 28 & 24 & 53,8 & 1 \\
\hline \multicolumn{5}{|l|}{ Pengetahuan preeklampsia } \\
\hline EMA & 50 & 2 & 96,2 & $4,54(2,68-7,70)$ \\
\hline Kontrol & 11 & 41 & 21,2 & 1 \\
\hline \multicolumn{5}{|c|}{ Sikap Manajemen Aktif Kala III } \\
\hline EMAS & 45 & 7 & 86,5 & $2,50(1,69-3,69)$ \\
\hline Kontrol & 18 & 34 & 34,6 & 1 \\
\hline \multicolumn{5}{|l|}{ Sikap preeklampsia } \\
\hline EMAS & 52 & 0 & 100 & $2,17(1,62-2,91)$ \\
\hline Kontrol & 24 & 28 & 42,6 & 1 \\
\hline \multicolumn{5}{|c|}{ Keterampilan Manajemen Aktif Kala III } \\
\hline EMAS & 48 & 4 & 92,3 & $1,23(1,01-1,47)$ \\
\hline Kontrol & 39 & 13 & 75,0 & 1 \\
\hline \multicolumn{5}{|l|}{ Keterampilan preeklampsia } \\
\hline EMAS & 32 & 20 & 61,5 & $32,0(4,54-225,57)$ \\
\hline Kontrol & 1 & 51 & 1,9 & 1 \\
\hline
\end{tabular}


Dari tabel 2 didapatkan hasil bahwa secara statistik terdapat hubungan antara program EMAS dengan hasil yang diharapkan (luaran) yang lebih baik dibanding yang tidak mendapat paparan program EMAS. Hal ini bisa diartikan bahwa paparan program EMAS ada hubungannya dengan peningkatan pengetahuan, perbaikan sikap, dan peningkatan keterampilan bidan baik di bidang managemen aktif kala tiga dalam rangka menurunkan resiko perdarahan post partum maupun pemberian magnesium sulfat pada kaus PEB pra rujukan untuk stabilisasi haemodinamik.

\section{Pengaruh variabel pengganggu terhadap hasil yang diharapkan.}

Untuk dapat mengetahui variabel manakah yang paling berpengaruh terhadap hasil yang diharapkan maka digunakan analisis multivariat dengan menggunakan metode regresi logistik. Hasil dari analisis tersebut dapat dilihat pada tabel berikut.

Tabel 3. Analisis regresi logistik keterampilan pemberian magnesium sulfat pada kasus pre eklampsia pra rujukan.

\begin{tabular}{|c|c|c|c|}
\hline Variabel & OR (ExpB) & $95 \% \mathrm{Cl}$ & Nilai P \\
\hline \multicolumn{4}{|l|}{ EMAS } \\
\hline \multirow{2}{*}{$\begin{array}{l}\text { Terpapar } \\
\text { Tidak terpapar }\end{array}$} & 26,64 & $7,98-88,96$ & 0.00 \\
\hline & 1 & & \\
\hline \multicolumn{4}{|l|}{ Usia } \\
\hline \multirow{2}{*}{$\begin{array}{l}<=30 \text { thn } \\
>30 \text { thn }\end{array}$} & 0,33 & $0,09-1,23$ & 0.10 \\
\hline & 1 & & \\
\hline \multicolumn{4}{|l|}{ Lama kerja } \\
\hline $\begin{array}{l}<=5 \text { thn } \\
>5 \text { thn }\end{array}$ & $\begin{array}{c}1,13 \\
1\end{array}$ & $0,31-4,11$ & 0.86 \\
\hline \multicolumn{4}{|l|}{ Pelatihan PPGDON } \\
\hline Pernah & 5,95 & $1,76-20,07$ & 0.004 \\
\hline Belum pernah & 1 & & \\
\hline
\end{tabular}

Dari tabel 3, didapatkan hasil bahwa paparan program EMAS dan pelatihan PPGDON meningkatkan keterampilan pemberian magnesium sulfat secara statistik bermakna dengan nilai $p<0,05$. Paparan program EMAS meningkatkan keterampilan bidan 26 kali dibanding yang tidak terpapar. Pelatihan PPGDON meningkatkan keterampilan pemberian magnesium sulfat responden 6 kali dibanding yang belum pelatihan PPGDON. Variabel pengalaman kerja meningkatkan keterampilan responden dengan OR: 1,13; (Cl: 0,31-4,11) tetapi secara statistik tidak bermakna.

Sebanyak 104 responden (bidan) yang terdiri dari terpapar program Expanding Maternal and Neonatal Survival (EMAS) sebanyak 52 responden dan 52 yang lainnya adalah responden yang tidak terpapar program EMAS (kontrol), tampak sebanding dalam usia, lama bekerja (pengalaman kerja), dan pelatihan PPGDON yang di tunjukkan dengan nilai $p<0,05$. Dari hasil analisis bivariat dengan tabel $2 \times 2$ didapatkan hasil bahwa secara statistik terdapat hubungan antara program EMAS dengan hasil yang diharapkan (luaran) yng lebih baik dibanding yang tidak mendapat paparan program $E M A S$, hal ini ditunjukkan dengan nilai $p<0,05$. Hal ini bisa diartikan bahwa paparan program EMAS ada hubungannya dengan peningkatan pengetahuan, perbaikan sikap, dan peningkatan keterampilan bidan baik di bidang managemen aktif kala tiga dalam rangka menurunkan resiko perdarahan post partum maupun pemberian magnesium sulfat pada kaus PEB pra rujukan untuk stabilisasi haemodinamik.

Paparan program EMAS dan pelatihan PPGDON meningkatkan keterampilan pemberian magnesium 
sulfat secara statistik bermakna dengan nilai $\mathrm{p}<0,05$. Paparan program EMAS meningkatkan keterampilan bidan 26 kali dibanding yang tidak terpapar. Pelatihan PPGDON meningkatkan keterampilan pemberian magnesium sulfat responden 6 kali dibanding yang belum pelatihan PPGDON. Variabel pengalaman kerja meningkatkan keterampilan responden dengan $\mathrm{OR}$ : 1,13; $(\mathrm{Cl}$ : 0,314,11) tetapi secara statistik tidak bermakna. Responden yang mendapat paparan program EMAS dan yang mendapat pelatihan PPGDON lebih terampil dibanding yang tidak terpapar ataupun tidak pelatihan. Hal ini menunjukkan bahwa paparan program EMAS dan pelatihan PPGDON adalah penting untuk meningkatkan kemampuan responden memberikan magnesium sulfat pada kasus preeklampsia pra rujukan.

\section{KESIMPULAN DAN SARAN}

Didapatkan perbedaan yang bermakna dalam hal pengetahuan, sikap, perilaku dan keterampilan bidan dalam hal managemen aktif kala tiga dan pemberian magnesium sulfat pada kasus pre eklampsia berat pra rujukan reponden (bidan) yang mendapatkan paparan program Ekspanding Maternal And Neonatal Survival (EMAS) dibanding yang tidak terpapar.

\section{DAFTAR PUSTAKA}

1. Expanding Maternal and Neonatal Survival (EMAS), http://kebijakankesehatanindonesia.net/ images/2012/SLLO/EMAS\%20overview\%20PIT\%20 HOGSI_ed.pdf

2. PROFIL KESEHATAN KABUPATEN KEBUMEN TAHUN 2014, http://www.pusdatin.kemkes. go.id/resources/download/profil/PROFIL_KAB_ KOTA_2014/3305_Jateng_Kab_Kebumen_2014.pdf

3. USAID. 2012. Menyelamatkañ ibu dan bayi baru lahir. Simulasi PEB / Eklamsia (2012). 9-10.

4. Cherrington, David J. 1995. The Management of Human Resources (4 ${ }^{\text {th }}$ Edition). New Jersey: Prentice Hall Inc.

5. Notoatmodjo, S. 1993. Metode Penelitian IImiah. In: S. G. Hunneryager \& I. L. Heckman. Metodologi Penelitian Kesehatan. Jakarta: Rineka Cipta. 1993: 18-20; 122

6. Azwar, s. 2005. Penyusunan Skala Psikologi. Dalam: Azrul. Pengembangan Sekala Sikap Terhadap Kerja. Yogyakarta: Pustaka Belajar, 2005: 11-21. 